\title{
Verheggen on Davidson and Kripke on Rule-Following and Meaning
}

\author{
ALEXANDER MILLER University of Otago
}

ABSTRACT: This paper discusses Claudine Verheggen's account of what she takes to be Donald Davidson's response to the sceptical paradox about rule-following and meaning developed in Saul Kripke's interpretation of Wittgenstein's 'rule-following considerations.' It focusses on questions about the normativity of meaning, the social character of meaning, and the role of triangulation in Davidson's account of the determination of meaning, and invites Verheggen to compare the non-reductionism she finds in Davidson with that developed in Crispin Wright's judgement-dependent account of meaning.

RÉSUMÉ : Cet article examine ce que Claudine Verheggen considère comme étant la réponse de Donald Davidson au paradoxe sceptique développé dans l'interprétation qu'offre Saul Kripke des remarques de Wittgenstein sur la possibilité de suivre une règle. Je me concentre en particulier sur des questions concernant la normativité de la signification, le caractère social de la signification et le rôle que la notion de triangulation joue dans la position de Davidson sur la détermination de la signification. J'invite aussi Verheggen à comparer le non-réductionnisme davidsonien avec celui défendu par Crispin Wright dans sa conception de la signification en tant que dépendante du jugement.

Keywords: Davidson, rule-following, Wittgenstein, Kripke, Wright

It is a great privilege to comment on Claudine Verheggen's contribution to this very stimulating book ${ }^{1}$ : her work reveals many potentially important points of

1 Myers and Verheggen, Donald Davidson's Triangulation Argument: A Philosophical Inquiry. Unless otherwise specified, all references are to this.

Dialogue 59 (2020), 207-217

(C) Canadian Philosophical Association/Association canadienne de philosophie 2020 doi:10.1017/S0012217320000049 
contact between late-Wittgensteinian and late-Davidsonian inquiries that have been hitherto neglected, and will repay careful study by anyone interested in either. In this brief commentary, I will merely ask some (I hope, friendly) questions about the approach to meaning that Verheggen attributes to Donald Davidson.

\section{Normativity and Meaning}

Verheggen represents Davidson as putting forward a form of semantic nonreductionism that can yield a response to the sceptical argument adumbrated in Chapter 2 of Saul Kripke's celebrated discussion of Wittgenstein's rulefollowing considerations. ${ }^{2}$ Although facts about "sheer associations between expressions and extra-linguistic items"3 are not capable of determining facts about meaning, facts about the meanings of speakers' words are "determined ... by the features of their environment on which they have triangulated linguistically and which they have agreed to take as the relevant aspects determining the meanings of their words," 4 where linguistic triangulation is a process that takes place in a semantic context, a context in which facts about what speakers mean or think are assumed to obtain.

I'll come back to non-reductionism in due course, but first I want to ask some questions about normativity and the social character of meaning. In the second chapter, Verheggen suggests that the Davidsonian view is hospitable to what is known in the literature as meaning engendered normativity (the idea that meaning opens up space for normative assessment of speakers and their linguistic usages, but is not necessarily itself a product of prior conventional norms). This emerges from a discussion of a familiar sort of objection to the idea that meaning is normative in a sense beyond the trivial sense imported by its generating correctness conditions. In response to this, Verheggen argues that on the Davidsonian position, meaning is normative in a sense that is "far from trivial" 5 and "over and above its being trivially normative.",

It is usually agreed on all sides that meaning is normative in the sense that it generates hypothetical prescriptions (e.g., (i) if I mean chair by 'chair' then if I want to tell the truth, I ought to apply 'chair' to an object $\mathrm{x}$ only if $\mathrm{x}$ is a chair). It is often objected that this cannot make meaning normative in any sense over and above the trivial since, for example, facts about the weather imply hypothetical

\footnotetext{
2 Kripke, Wittgenstein on Rules and Private Language.

3 P. 90.

4 P. 90.

5 P. 42.

6 P. 62.
} 
prescriptions too (e.g., (ii) if it is raining outside, then if I want to stay dry, I ought to take an umbrella), but no one thinks that facts about the weather are normative. Against this, Verheggen argues that there is an important disanalogy between the weather case and the meaning case. Unlike facts about the weather, facts about meaning essentially generate hypothetical prescriptions, and this difference turns on the fact that speakers themselves contribute, via participation in triangulation, to the constitution of what their words mean, while no such contribution is made to the constitution of the facts about the weather. The argument here is subtle, but it seems to go along the following lines. In order for the hypothetical 'oughts' generated by the fact that it is raining not to apply to me, it is enough that I am indifferent to whether or not I get wet. If I am indifferent to the rain, it is not the case that I ought to take an umbrella, but the fact that it is raining remains in existence. In contrast, since I myself contribute to a process that determines that, e.g., I mean sunny by 'sunny,' indifference on my part to whether or not I produce meaningful utterances would lead to it no longer being the case that I mean sunny by 'sunny.' So in this case if indifference on my part leads to the suspension of the relevant hypothetical 'oughts,' that can only be because the erstwhile fact that I meant sunny by 'sunny' no longer obtains. (There are some changes in desire that leave the meaning fact intact and generate changes in the relevant 'oughts' — if I want to trick you into visiting Glasgow in late December, I ought to tell you that it is usually very sunny, but unlike the weather case, facts about meaning are constituted "not altogether independently of my desire."7)

I'll make two comments about this. First, the argument seems to depend on some principle to the effect that if I have a say in the constitution of a fact, that fact cannot remain intact if I subsequently become indifferent to it. It's not obvious how good this principle is. For example, I may have a say in the constitution of the fact that I promise to spend less time on Facebook. If desire subsequently leads me to spend even more hours of the day scrolling down the screen, don't we want to say that the fact that I promised to spend less time on Facebook is still intact, and that it is precisely because of this that my current behaviour can be said to be in violation of it? Likewise, in the meaning case, couldn't it be that the way in which I contribute to the constitution of the fact that I mean sunny by 'sunny' leaves it intact even if I subsequently no longer desire to produce meaningful utterances? Perhaps the conditions in which I learned how to use the word trump any subsequent changes in desire.

Second, I suspect that it doesn't really undermine the standard antinormativist point made by those who deny that meaning facts are normative in any sense over and above the trivial. As anti-normativists see it, the point about the weather is an illustration of the fact that hypothetical prescriptions do not generate any genuine normativity. Consider an example that I think

$7 \quad$ P. 60. 
originates with R.M. Hare: the statement 'If you want to go to the largest grocer in Oxford, you ought to go to Grimbly Hughes,' although it contains an 'ought,' is actually equivalent to the purely descriptive statement 'Grimbly Hughes is the largest grocer in Oxford. ${ }^{8}$ So, hypothetical prescriptions don't generate genuine normativity. This is illustrated by the fact that weather facts generate hypothetical prescriptions but are clearly not normative, but even if the generation of hypothetical prescriptions is, as Verheggen claims, essential to meaning, unless the 'Grimbly Hughes' argument is overturned, this won't show that meaning is normative in a sense over and above the trivial. So, Verheggen appears to have mistaken an illustration of the anti-normativist position with an argument for it, and consequently underplayed the real anti-normativist consideration. Summarising this discussion, Verheggen writes: "only hypothetical implications follow from [ascriptions of meaning], but, contra the anti-normativists ... these implications are essential to meaning." Again, though, the anti-normativist needn't deny that these implications are essential, but can argue that, although essential, they don't engender any genuine normativity. Meaning could indeed be essentially hypothetically prescriptive but still fail to be normative in any sense beyond the trivial.

\section{Communitarian and Interpersonalist Views of Language}

Verheggen distinguishes between communitarian views of language, according to which "having a (first) language essentially depends on meaning by one's words what members of some community mean by them,"10 and interpersonal views, which hold that "the possession of language and thought essentially depends on having triangulated linguistically with others ... [but] does not require that the triangulators assign the same meanings to the same words." ${ }^{11}$ She represents Kripke as putting forward a communitarian view of this sort in response to his inability to find facts capable of making it the case that expressions mean what they do:

Kripke's answer is that ascriptions of meaning to a speaker's utterances have assertibility conditions rather than truth-conditions. They are justified if the speaker's applications of her words agree consistently with those made by competent members of her community. (They are also justified in terms of the role and utility they have in people's lives.) Thus, in effect, the meanings of a speaker's words are determined by what the members of her community mean by those words. Correct applications are applications that conform to the conditions of correctness at play in her community. ${ }^{12}$

\footnotetext{
8 See Hattiangadi, "Is Meaning Normative?," p. 228.

9 P. 4.

10 P. 84 .

11 P. 84.

12 P. 90.
} 
It seems to me that Verheggen is here in danger of ascribing a communitarian straight solution to Kripke's Wittgenstein, ${ }^{13}$ thereby missing the distinctively sceptical nature of the solution that forms the centrepiece of his account. Let the assertibility conditions of a sentence $\mathrm{S}$ be the conditions under which speakers are licensed to assert $\mathrm{S}$, and let the truth-conditions of $\mathrm{S}$ be the conditions whose obtaining is necessary and sufficient for S's truth. On a realist, truthconditional picture of meaning, the fact that $\mathrm{S}$ has the assertibility conditions it has will be explained in terms of its having the truth-condition that it has. Thus, that I am licensed to assert 'It is snowing in Dunedin' by the fact that there are white flakes falling down outside can be explained by the relationship between that fact and the sentence's truth-condition: there is a causal or empirical relationship between the falling of the snow and my seeing white flakes outside my window. Verheggen appears to attribute a view like this to Kripke in the passage above: my agreement with the other members of my community determines that I mean addition by ' + ,' and this fact about agreement with what the community means explains why the assertion of "Alex means addition by "+"” is licensed when my answers to arithmetical queries involving ' + ' are more or less the same as those that members of my community are inclined to give. However, this cannot be right; at this point in the dialectic, the realist, truthconditional picture of meaning has been given up, and has been replaced with the idea that the practice of asserting the relevant sentence under the relevant conditions is justified by the utility of the practice that licenses the assertion of the sentence under those conditions, rather than by a relationship between the obtaining of the assertibility conditions and the obtaining of a truth-condition.

So, in describing the sceptical solution, we should leave to one side the idea that what I mean might be determined by facts about agreement with the meanings assigned to expressions by members of my community, and instead ask after the conditions in which ascriptions of meaning are asserted and the utility and role of the practice of allowing their assertion under those conditions. I will suggest that, when we do this, it turns out that the sceptical solution is in fact consistent with the sort of interpersonal view associated with Davidson.

Consider the familiar sort of thought experiment in which Smith, a lifelong solitary considered in isolation from any community, is inclined to utter 'I mean blue by "blue".' In this scenario, what is the assertibility condition of "Smith believes that he means blue by "blue"'? The only possibility would appear to be provided by his inclination to utter "I mean blue by "blue".' Since Smith here is a lifelong solitary and we are not invoking the inclinations of any community, this will also be the assertibility condition for 'Smith means blue by "blue".' Thus, in this scenario, the assertibility conditions of 'Smith

13 By 'Kripke's Wittgenstein' here and elsewhere I mean Wittgenstein as interpreted by Kripke in Wittgenstein on Rules and Private Language. 


\section{Dialogue}

believes that he means blue by "blue"" and "Smith means blue by "blue" will be identical, so that 'whatever seems right to Smith will be right,' and the 'seems right'/'is right' distinction necessary for the propriety of meaning talk is not available.

Now compare this with the situation in which Smith is no longer considered in isolation from any community. The assertibility condition for 'Smith believes that he means blue by "blue" will be as before, but now the assertibility condition for "Smith means blue by "blue" will be that Smith is inclined to use 'blue' in ways that agree with the inclinations of the community (on the assumption that the community judges that it means blue by 'blue'). So the assertibility conditions of 'Smith believes that he means blue by "blue", and "Smith means blue by "blue"" can come apart, and the 'seems right'/'is right' distinction is preserved. And, apparently, in order for it to be assertible that Smith means something by his words, there has to be a measure of agreement with the inclinations of the community, and this is what gives the sceptical solution the appearance of communitarianism in the sense defined by Verheggen.

However, we can ask: is it possible within the framework provided by the sceptical solution for it to be assertible that an individual speaker means something different by an expression from what the community means by it? It seems to me that an affirmative answer can be given here: this will be assertible when the individual concerned is inclined to use the expression in the way the community would be inclined to use it were they to judge that they mean what he says he means by it. For example, suppose that Smith is inclined to utter 'I mean rectangular by "blue".' As before, this will be taken to license the assertion of 'Smith believes that he means rectangular by "blue".' But the assertibility condition of "Smith means rectangular by "blue" will be that Smith is inclined to use 'blue' in a way that agrees with how the community would use it were they to judge that they mean rectangular by 'blue' — and, crucially, this can be the case even if the community judges that it in fact means something else (e.g., blue) by 'blue.'

So, the sceptical solution can incorporate the idea that agreement with such counterfactual inclinations of the community will license the assertion that the individual means something different by an expression from what the community takes itself to mean. And, despite the fact that this does not amount to agreement with the community's actual use of the word, it will often be enough in practice to give members of the community what they require for interpreting and understanding the individual. This preserves the utility that the sceptical solution views meaning ascriptions as possessing: when a community member says that Smith means so and so by an expression, she thereby signals to her fellow community members that they can expect Smith to act as the community would were it to mean so and so by the expression, and this expectation can provide enough for interpretation and understanding, even if the community does not in fact mean so and so by the expression in question. Thus, it is consistent 
with the sceptical solution that a speaker can mean something by her words and be understood as doing so - even if she means something different by those words from her interpreters. So, there is nothing in the sceptical solution in itself that renders it inconsistent with the Davidsonian interpersonal view that Verheggen prefers. (Matters are actually a little more complicated here due to the need to eliminate reference to community judgement: I attempt to deal with some of the complications in work-in-progress.)

\section{The First-Person Epistemology and "Disposition-Like Theoreticity" of Meaning}

Kripke's discussion of non-reductionism is notoriously brief. He writes:

[I]t seems desperate: it leaves the nature of the postulated primitive state - the primitive state of meaning addition by 'plus' - completely mysterious. It is not supposed to be an introspectible state, yet we are supposedly aware of it with some fair degree of certainty whenever it occurs. For how else can each of us be confident that he does, at present, mean addition by 'plus'? ${ }^{14}$

Crispin Wright argues that this passage, brief as it is, does contain the ingredients for a substantive challenge to non-reductionism. On the one hand, the firstperson epistemology of meaning is, like the first person-epistemology of intention, first-person authoritative and non-inferential: I know that I intend to travel to Scotland later this week without having to infer this from anything, and my avowal that I have this intention, although it can be overturned in certain circumstances, stands as the default in the absence of information that I am selfdeceived or insincere or similar. On the other hand, ascriptions of meaning and intention display what Wright calls "disposition-like theoreticity": they "have to answer, after the fashion of dispositions, to what one says and does in situations so far unconsidered." ${ }^{, 15}$ The challenge is to answer the question: how is it possible for there to be states that simultaneously exhibit first-person authority and disposition-like theoreticity? ${ }^{16}$

Wright takes this to be the take-home message of Kripke's remarks in the passage above, and develops the idea that meaning and intention are, as he puts it, judgement-dependent, in an attempt to show how a non-reductionist response to

\footnotetext{
14 Kripke, Wittgenstein on Rules and Private Language, p. 51.

15 Wright, Rails to Infinity, p. 150.

16 Wright. See in particular "Wittgenstein's Rule-Following Considerations and the Central Project of Theoretical Linguistics" and "Critical Notice of McGinn's Wittgenstein on Meaning."
} 


\section{Dialogue}

Kripke might speak to the challenge. John McDowell, however, rejects the question, and true to his quietism, makes no attempt to answer it. ${ }^{17}$ Verheggen, however, takes neither of these routes. As far as I can see, there is no attempt to address the issue about first-person authority that Wright takes to be Kripke's main challenge to non-reductionism, and Verheggen explicitly distances the form of non-reductionism she attributes to Davidson from philosophical quietism. ${ }^{18}$ So, my question for Verheggen is: what is the Davidsonian response to the challenge of squaring the first-person epistemology of meaning with its disposition-like theoreticity?

\section{Constraints on Triangulation-Based Accounts of Meaning}

As I noted above, by way of responding to Kripke's challenge, Wright himself explores the idea that meaning might be judgement-dependent. In general, we can think of F-ness as a judgement-dependent property (or equivalently, of the truth about F-ness as judgement-dependent) if a 'provisional equation' like the following satisfies certain constraints:

(iii) $(\forall x)(C \rightarrow(S$ judges that Fx iff Fx $))$,

where ' $\mathrm{C}$ ' denotes conditions that are cognitively ideal for making judgements about F-ness. The constraints are (a) that (iii) be a priori, (b) that the $\mathrm{C}$-conditions be specifiable non-trivially, (c) that whether the C-conditions actually obtain be logically independent of facts about the instantiation of F-ness, and (d) that there be no better explanation of (a) to (c) than the idea that the truth about F-ness be determined by optimal, that is to say, C-conditioned judgement about F-ness. Wright thinks that we may be able to make a case that a bi-conditional along these lines for self-ascriptions of intention satisfies the various constraints, and that, given that the case of intention is analogous to that of meaning, we can say that the truth about self-ascriptions of intention and meaning is determined by optimal judgement: in short, that the truth about self-ascriptions of intention and meaning is judgement-dependent. ${ }^{19}$ Now, many of the things Verheggen says in her exposition of the

17 See, e.g., McDowell, "Meaning and Intentionality in Wittgenstein's Later Philosophy."

P. 2.

19 I'm oversimplifying hugely here: see Wright's "Wittgenstein's Rule-Following Considerations and the Central Project of Theoretical Linguistics," especially Sections III and IV, for some of the relevant detail. For the general notion of judgement-dependence, see Wright's "Moral Values, Projection and Secondary Qualities" and the appendix to Chapter 3 in his Truth and Objectivity. 
Davidsonian view sound roughly along the lines of a judgement-dependent account. For example:

[T] he question of what one means by one's utterances and what thoughts one has can be answered only within a semantic context, by saying that one means or thinks such and such or so and so. ${ }^{20}$

It is ... what she thinks her terms mean, that determines what they do mean. ${ }^{21}$

Now, clearly not just any claim about what one means will be determinative of what one means: on the Davidsonian account, it is what one says after having engaged in triangulation that determines what one means. So consider:

(iv) $\mathrm{T} \rightarrow$ (S judges that he means table by 'table' iff he means table by 'table').

Here ' $\mathrm{T}$ ' stands for a process of triangulation in which $\mathrm{S}$ has interacted linguistically with another speaker in the presence of tables, where 'linguistic interaction' includes negotiating an agreement about what S means by 'table.' In order to help us place the Davidsonian suggestion advocated by Verheggen, I want to ask: what constraints does (iv) have to satisfy in order for us to be able to conclude that S's meaning table by 'table' is determined by her saying that she means table by 'table'? For example, can we spell out in detail what linguistic triangulation involves in a way that avoids a trivialising reading like 'a process that ensures that $\mathrm{S}$ means what he says he means'? Is the fact that the triangulation process has taken place logically independent of facts about what $\mathrm{S}$ means by 'table'? Now, I'm not defending Wright's judgement-dependent account of meaning and intention - I've criticised it in print myself on a number of occasions $^{22}$ - but it does aspire to give us a non-reductionist answer to the rule-following problem that is non-quietist insofar as it tries to explain how the first-person epistemology of meaning might mesh with its 'disposition-like theoreticity.' So, given that the triangulation-based account also aspires to provide us with a view of meaning that is both non-reductionist and non-quietist, comparing it with Wright's suggestion might help us to get clear on the nature of the former. What constraints does (iv) have to satisy in order for the triangulation-based account to be plausible? And, can a case be made out that it does in fact satisfy them? Alternatively, if the request for a comparison is in some way ill-conceived, it would be helpful to know why.

\footnotetext{
20 P. 3.

21 P. 40 n. 58.

22 See my "An Objection to Wright's Treatment of Intention," "Another Objection to Wright's Treatment of Intention," and "Primary Qualities, Secondary Qualities and the Truth About Intention."
} 


\section{Concluding Questions}

I'll end by summing up the questions I have raised for Verheggen:

(A) Does the argument that meaning facts are essentially hypothetically prescriptive assume that our involvement in the constitution of a fact entails that the fact cannot remain in existence if we become indifferent to it? And couldn't meaning facts be essentially hypothetically prescriptive even though hypothetical prescriptivity imports no normativity beyond the trivial?

(B) Does the account of Kripke's Wittgenstein's sceptical solution sketched in the third chapter of the book treat it as a straight form of communitarianism? And is Kripke's Wittgenstein's sceptical solution not in fact consistent with the Davidsonian interpersonal view?

(C) What is the Davidsonian response to the Kripke/Wright challenge to non-reductionism to square the first-person epistemology of meaning and intention with their 'disposition-like theoreticity'?

(D) What constraints does (iv) have to satisfy in order for it to be plausible that triangulation-mediated judgements about meaning determine the facts about meaning? And does it in fact satisfy them? Or if these are bad questions, why?

\section{Acknowledgements}

I am grateful to Olivia Sultanescu for organising the symposium at the meeting of the Canadian Philosophical Association in Montreal and for inviting me to contribute, and to all the participants for making it such a stimulating occasion. I am also grateful to Fiona MacPherson for inviting me to visit the Centre for the Study of Perceptual Experience at the University of Glasgow in June 2018, and to the participants in the Glasgow reading group on normativity, especially Samuele Chivlovi, Stephan Leuenberger, George Pavlakos and Glen Pettigrove. Thanks also to Anandi Hattiangadi.

\section{References}

Hattiangadi, Anandi

2006 "Is Meaning Normative?" Mind and Language 21(2): 220-240.

Kripke, Saul

1982 Wittgenstein on Rules and Private Language. Cambridge, MA: Harvard University Press.

McDowell, John

1992 "Meaning and Intentionality in Wittgenstein's Later Philosophy." Midwest Studies in Philosophy 17(1): 40-52. 
Miller, Alexander

1989 "An Objection to Wright's Treatment of Intention." Analysis 49(4): $169-173$

Miller, Alexander

2007 “Another Objection to Wright's Treatment of Intention.” Analysis 67(3): 257-263.

Miller, Alexander

2009 "Primary Qualities, Secondary Qualities and the Truth About Intention." Synthese 171(3): 433-442.

Myers, Robert H., and Claudine Verheggen

2016 Donald Davidson's Triangulation Argument: A Philosophical Inquiry. New York: Routledge.

Wright, Crispin

1988 "Moral Values, Projection and Secondary Qualities." Aristotelian Society Supplementary Volume 62(1): 1-26.

Wright, Crispin

1989a "Wittgenstein's Rule-Following Considerations and the Central Project of Theoretical Linguistics," in his Rails to Infinity, pp. 170-213.

Wright, Crispin

1989b “Critical Notice of McGinn's Wittgenstein on Meaning," in his Rails to Infinity, pp. 143-169.

Wright, Crispin

1993 Truth and Objectivity. Cambridge, MA: Harvard University Press.

Wright, Crispin

2001 Rails to Infinity. Cambridge, MA: Harvard University Press. 